\title{
Entre o cárcere e a liberdade: apostas na produção cotidiana de modos diferentes de cuidar
}

Between prison and freedom: bets in the daily production of different modes of care Entre la cárcel y la libertad: apuestas en la producción cotidiana de diferentes modos de cuidar.

\section{Silvio Yasui}

Universidade Estadual Paulista, Assis, SP, Brasil.

\section{Resumo}

O texto apresenta algumas reflexões sobre o desafio da Reforma Psiquiátrica (RP) e da Política Nacional de Humanização (PNH) em mudar os modos de cuidar e produzir saúde no cotidiano dos serviços. Partindo de observações e inquietações sobre o atual cenário de ambas políticas, marcado por uma tendência conservadora como, por exemplo, pelas ações para o recolhimento e internação compulsória que autoridades municipais e estaduais estão implementando, o autor busca explicitar que o cuidado tem a liberdade como principio e exigência ética e que tais medidas afrontam este principio representando um preocupante retrocesso na política pública de saúde mental. Destaca ao final que ambas as politicas (PNH e Saúde Mental) são apostas que se constroem nas bordas e fissuras deste mesmo cotidiano conservador, o que representa um imenso desafio.

Palavras-Chave: Saúde Mental, Direitos Humanos, Humanização

\begin{abstract}
This paper presents some reflections about the challenge of the Psychiatric Reform (RP) and the National Policy of Humanization (NHP) to change modes of production and health care. Starting at observations about the current scenario, marked by a conservative tendency, the author seeks to explain the care that has freedom as a principle and ethical requirement and that compulsory admissions represents a worrying setback in the public mental health policy. At the end the author points out that both policies (PNH and Mental Health) are bets which are produced in nooks and crevices of the conservative model, which represents an immense challenge.
\end{abstract}

Key words: Mental Health, Human Rights, Humanization. 


\section{Resumen}

El artículo presenta algunas reflexiones sobre el desafío de la Reforma Psiquiátrica (RP) y la Política Nacional de Humanización (PNH) en cambiar los modos de producción y cuidado de la salud. A partir de observaciones sobre la situación actual de ambas políticas, marcadas por una tendencia conservadora, por ejemplo, las acciones de recogida y admisión obligatorio que las autoridades estatales y locales están llevando a cabo, el autor trata de explicar el cuidado que tiene la libertad como principio y la exigencia ética. $\mathrm{Y}$ esas medidas frente a este principio constituye un retroceso preocupante en la política de salud mental pública. En las notas finales que ambas políticas (PNH y Salud Mental) están apostando que se acumulan en los bordes y grietas del mismo diario conservador, lo que representa un inmenso desafío.

Palabras clave: Salud Mental, Derechos Humanos, Humanización

Desconfiai do mais trivial, na aparência singelo.

E examinai, sobretudo, o que parece habitual.

Suplicamos expressamente:

não aceiteis o que é de hábito como coisa natural,

pois em tempo de desordem sangrenta, de confusão organizada, de arbitrariedade consciente, de humanidade desumanizada, nada deve parecer natural, nada deve parecer impossível de mudar.

Bertolt Brecht

A epígrafe acima do dramaturgo Bertolt Brecht serve de mote e de inspiração para o presente texto que busca refletir sobre o desafio da Reforma Psiquiátrica (RP) e da Política Nacional de Humanização (PNH) em mudar os modos de cuidar e produzir saúde no cotidiano dos serviços.

Tomo como material, observações e inquietações sobre o atual cenário de ambas políticas e de alguns eventos que frequentam as páginas de jornal e a mídia de maneira geral, como por exemplo, a denúncia sobre a precária condição de cuidado em um hospital psiquiátrico na região de Sorocaba e as ações para o recolhimento e internação compulsória que autoridades municipais estão implementando.

Inicialmente, apresento quatro cenas em diferentes momentos históricos, extraídas da minha experiência pessoal:

Cena 01 - O ano é 1976. Desço do ônibus na rodovia Presidente Dutra e 
o motorista me aponta para uma estrada de chão batido. Sigo por ela por uns 3 quilômetros até chegar em uma imensa construção. Na porta a placa: Hospital Psiquiátrico. Sou recebido pela psicóloga que pergunta qual ano que estudo. “-Segundo", respondo com certo constrangimento. Com um olhar desanimado, ela pede a um auxiliar de enfermagem que me mostre o hospital. Caminho pelos corredores sentindo náuseas causadas pelo forte cheiro de urina, fezes e desinfetante barato. Chego ao pátio. Dezenas de pacientes deitados no chão, muitos seminus. Suas roupas estão quase todas rasgadas, sujas. Tenho a impressão de que são vários mendigos. Ao me verem, aproximam-se, pedem cigarro, dinheiro. Pedem, pedem. Uma solicitação, repetida por muitos chama a minha atenção: "-Me tira daqui!" .

Cena 02 - Sigo por uma longa estrada até chegar ao município de Franco da Rocha e logo chego à entrada do hospital. Entro e vislumbro os belos jardins do Juquery. Estamos no ano de 1983 e é minha primeira semana de trabalho. Sou recebido pelo diretor clínico que me informa: serei o único psicólogo disponível para a assistência (outro estava em um cargo administrativo). Sou eu para mais de
4000 internos. Vou conhecer algumas enfermarias. Chego ao pátio e vejo a mesma cena. Dezenas de pessoas deitadas no chão. Ao me verem, várias vêm em minha direção, pedindo cigarro, dinheiro. Pedem, pedem. Em muitos o mesmo pedido/súplica: “-Me tira daqui!".

Desta vez não era um estagiário voluntário. Engajo-me em um ousado projeto que visava mudar aquela instituição e transformar a vida daqueles pacientes. Realizaram-se contratações, novas internações foram proibidas, reformas foram realizadas. Participei mais diretamente no Projeto dos Lares Abrigados, uma proposta para mudar as unidades e dar conta da população de pacientes moradores ofertando um lugar e um cotidiano diferente do hospício. No cenário mais amplo, vários outros hospitais psiquiátricos iniciaram também importantes processos de mudança e ampliou-se o número de serviços ambulatoriais. Eram os primeiros movimentos da Reforma Psiquiátrica em São Paulo.

Cena 03 - O ano é 1997. Estou a caminho de um hospital psiquiátrico privado para realizar uma avaliação. Faço parte de uma equipe de Secretaria de Estado da Saúde que realizou várias vistorias nos hospitais com o objetivo 
de classificá-los e enquadrá-los nas, na época, novas normas oriundas a partir da portaria 224/92. São os primeiros movimentos que se fortalecerão poucos anos depois com o Programa Nacional de Avaliação dos Serviços Hospitalares (PNASH). Nova longa estrada até chegar ao hospital. Somos recebidos pela direção que se queixa dos baixos valores pagos pelo SUS. Ao entrarmos, percebo que a limpeza recente não oculta o que está impregnado nas paredes: o cheiro de fezes e urina. Novamente, no pátio, os pacientes estão com roupas novas demais para $\mathrm{o}$ momento. Ao nos verem, aproximam-se olhando temerosos o diretor que nos acompanha. Mesmo como sua presença intimidatória, muitos não se acanham e pedem cigarro, dinheiro. Pedem, pedem. Alguns pedem/suplicam: "-Me tira daqui!".

Cena 04 - O ano é 2012. Meus alunos comentam - "Assistiu na TV aquela reportagem denúncia sobre um hospital psiquiátrico?" Meses antes, na mesma região, foi criado o Fórum da Luta Antimanicomial de Sorocaba (FLAMAS) que denunciava o alto índice de mortes nos hospitais psiquiátricos. A reportagem exibia as mesmas cenas. Pacientes com roupas rasgadas ou seminus, deitados no pátio, forte cheiro de fezes e urina. Foco em um paciente que pede: “- Me tira daqui!".

Uma ampla mobilização de segmentos sociais para intervir no hospital é um avanço institucional relevante e não pode deixar de ser citado. Representantes de diversas instituições $^{2}$ realizaram uma importante ação conjunta para a realização de um censo com os seguintes objetivos: efetuar a identificação civil das pessoas internadas de forma a propiciar-lhes benefícios assistenciais e previdenciários; o levantamento dos principais dados psicossociais; e subsidiar a formulação de políticas públicas de saúde mental para a região com vistas à desinstitucionalização das pessoas ali internadas.

Contudo, a existência de um hospital psiquiátrico com as características asilares como o denunciado, após anos de Reforma Psiquiátrica, deixa-nos com certo gosto amargo na boca. Entre a primeira e a última cena passaram-se 36 anos. A Reforma Psiquiátrica transformou-se em uma ampla política pública, ampliando a rede de serviços e ações da saúde mental, reduzindo leitos psiquiátricos, aumentando o investimento na rede extra-hospitalar. 
Ao assistir a reportagem, é inevitável não sentir um certo desassossego, quase um desânimo, em constatar que, apesar de avançarmos em muitos aspectos, o manicômio ainda exibe a sua face mais cruel e violenta, nos encarando de modo desafiador.

Tal face tenebrosa ressurge, também, nas palavras e ações de prefeitos que investem pesado contra os dependentes químicos, propondo internação compulsória como recurso de tratamento, sendo aplaudido por amplos setores conservadores da sociedade e, especialmente, pelos donos de comunidades terapêuticas que certamente obterão lucros financeiros com estas medidas policialescas e higienistas. Ofertam o mesmo modo de tratar, mas seguem indiferentes à dor, ao sofrimento, à singularidade e à complexidade das vidas que são retiradas das ruas e enclausuradas. Quantos pedidos de “- Me tira daqui!” ainda são necessários? "Os processos de "anestesiamento" de nossa escuta, de produção de indiferença diante do outro, têm nos produzido a enganosa sensação de salvaguarda, de proteção do sofrimento" (Brasil, 2009, p.12).

O trecho acima citado é da Cartilha da PNH sobre Acolhimento e Classificação de Risco e alerta para os efeitos danosos de uma crescente mercantilização das relações entre os sujeitos e da vida. Efeitos que se corporificam no cotidiano dos serviços de saúde e, de uma forma mais inquietante ainda, nos serviços de saúde mental. Anestesia, esquecimento ou indiferença a uma diretriz vital para mudar nosso modo de cuidar do sofrimento psíquico: liberdade.

Em um artigo, Nicácio e Campos (2007) abordam a relevância e a necessária afirmação da liberdade para a superação do modelo asilar. No início do texto apresentam títulos de documentos do Ministério da Saúde, que tratam da liberdade como tema: "Saúde mental: cuidar em liberdade e promover a cidadania" (Brasil, 2004). "Liberdade é o melhor cuidado" (Brasil, 2001). Acrescentaria a esta lista mais dois itens: um caderno de textos organizado pelo Conselho Regional de Psicologia-06 intitulado "Trancar não é tratar": e a frase transformada em um cartaz e repetida muitas vezes pelos militantes da luta antimanicomial: "Saúde não se vende, loucura não se prende".

No texto os autores retomam a produção do psiquiatra italiano Franco Basaglia, especialmente suas reflexões sobre a experiência como diretor do 
Hospital Psiquiátrico de Gorizia, onde, ao se deparar com a violência do manicômio e a destruição das pessoas internadas, inicia um radical processo de crítica e de transformação da instituição. Seus escritos problematizaram a condição da pessoa internada e os significados do manicômio, questionando a psiquiatria, seus instrumentos e sua finalidade como ciência. Basaglia destacava que a transformação da condição do paciente internado exigia a criação de propostas que tivessem por princípio a sua liberdade.

Uma de suas mais famosas expressões, inspirada na fenomenologia de Husserl e como profunda crítica à objetivação do homem pela psiquiatria positiva, é a de "colocar a doença entre parênteses", o que se traduzia no cotidiano em um intenso trabalho de produzir ações plurais, responsabilizarse pelo cuidado do paciente, identificar sua necessidade, escutar seu sofrimento, iniciando a:

"Produção de uma diversa e complexa prática terapêutica pautada na compreensão da pessoa, na transformação de suas possibilidades concretas de vida, a partir da construção cotidiana do encontro e da intransigente afirmação da liberdade" (Nicácio, Campos, 2007:146).

$\mathrm{Na}$ perspectiva basagliana, liberdade não é resultado e sim base da prática terapêutica.

Ou seja, não é possível pensar o cuidado ao sofrimento psíquico considerando-o apenas como um diagnóstico resultante das disfunções de interações neurobioquímicas, nem tampouco com práticas que restrinjam ou limitem o exercício do ir e vir, que incidam sobre o já precário poder de contratualidade que o sujeito tem sobre si e sobre as coisas do mundo. Muito menos com práticas que o submetam a um regime de controle e vigilância sobre todas as suas ações cotidianas. $\mathrm{O}$ resultado histórico deste modo de pensar a dor psíquica é bem conhecido: segregação, violência institucional, isolamento, degradação humana.

Nicácio e Campos (2007) destacam que pensar o cuidado em liberdade, provoca inovações na prática terapêutica, inscreve novas profissionalidades, e representa uma nova projetualidade nos processos de coproduzir com as pessoas com a experiência do sofrimento psíquico projetos de vida nos territórios.

Trata-se aqui de deslocar-se do Manicômio como o lugar zero de trocas 
sociais (Rotelli, 2001) e da doença como objeto simples, para o território, plano do cotidiano no qual o sofrimento psíquico tomado como objeto complexo, implica a vida em suas múltiplas dimensões e cuja perspectiva de cuidado, portanto, significa atuar na transformação da subjetividade e dos modos de viver.

É um ousado projeto de um cuidado que se constrói a partir de criações produzidas em encontros que coproduzem sujeitos e projetos de vida. Coprodução dos sujeitos só pode ser feita em liberdade regida pela ética da autonomia. É um projeto ético-estéticopolítico:

- ético no que se refere ao compromisso com o reconhecimento do outro, na atitude de acolhê-lo em suas diferenças, suas dores, suas alegrias, seus modos de viver, sentir e estar na vida;

- estético porque traz para as relações e os encontros do dia-a-dia a invenção de estratégias que contribuem para a dignificação da vida e do viver e, assim, para a construção de nossa própria humanidade;

- político porque implica o compromisso coletivo de envolver-se neste "estar com", potencializando protagonismos e vida nos diferentes encontros. (Brasil, 2010, p. 6)
A citação acima refere-se à diretriz do Acolhimento da Política Nacional de Humanização, mas se aplica perfeitamente ao que argumentávamos sobre o projeto da Reforma Psiquiátrica. Isto evidencia como ambas políticas compartilham dos mesmos princípios e posicionamentos ético-estético e político. Falamos aqui da produção do cuidado ao sofrimento psíquico, indissociável da produção de saúde. Falamos aqui da construção e da consolidação do SUS. Para a PNH, o SUS humanizado é aquele que reconhece o outro como legítimo cidadão de direitos, valorizando os diferentes sujeitos implicados no processo de produção da saúde. Humanização do SUS é entendida como:

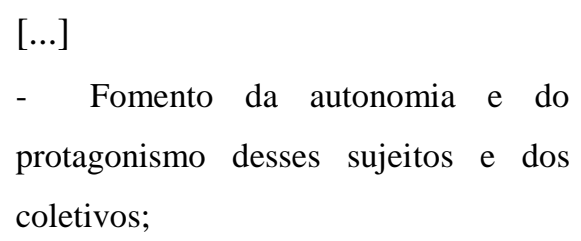
protagonismo desses sujeitos e dos coletivos;

- Aumento do grau de coresponsabilidade na produção de saúde e de sujeitos;

- Estabelecimento de vínculos solidários e de participação coletiva no processo de gestão;

- Mapeamento e interação com as demandas sociais, coletivas e subjetivas de saúde;

- Defesa de um SUS que reconhece a diversidade do povo brasileiro e a todos 
oferece a mesma atenção à saúde, sem distinção de idade, raça/ cor, origem, gênero e orientação sexual [...] (Brasil, 2008, p. 18-19)

Podemos afirmar que tanto a PNH quanto a RP, buscam se impor como força de resistência ao atual projeto hegemônico de sociedade que menospreza a capacidade inventiva e autônoma dos sujeitos. É uma aposta na potência que emerge no reposicionamento dos sujeitos, ou seja, no seu protagonismo, na potência do coletivo, na importância da construção de redes de cuidados compartilhados: uma aposta política (Pasche \& Passos, 2008)

Aposta que encontra enormes resistências e obstáculos. Ao olharmos para a corrente conservadora que ainda domina amplos setores da sociedade e que se refletem nos modos de se fazer a gestão na saúde, como as recentes ações para internação compulsória dos dependentes químicos, temos a sensação de que estamos muito distantes de ver implantada os princípios que acima nomeamos. É o que frequentemente escuto quando discuto estas questões com os trabalhadores da saúde. Via de regra afirmam tratar-se de um bonito discurso e apenas isso. Parece que a dura realidade cotidiana é imutável e impermeável a qualquer tentativa de mudança. Frases como "Usuário é assim mesmo!", “A gente nunca consegue nada, não somos gestores”, “O problema da saúde é que todo mundo é funcionário público" "Paciente em crise precisa de hospital psiquiátrico" e outras tantas, expressam as forças conservadoras presentes nos modos de pensar/agir que continuam a nos atravessar seduzindo-nos a sermos acomodados.

A rigidez dos processos de trabalho e a organização dos serviços de saúde, modos de cuidar centrados na doença; trabalhadores destituídos da capacidade de decidir e usuários que só são escutados, impacientemente, em suas queixas: tudo isso contribuiu para uma naturalização do cotidiano produtor de indiferença ao sofrimento do outro, uma máquina de reprodução de relações de assujeitamento, heteronomias, subjetividades servis e tristes.

Neste cenário, instituir como política de saúde a internação compulsória/cárcere dos usuários de crack é retroceder a medidas arcaicas e ineficazes. É insistir no erro histórico que a Reforma Psiquiátrica tanto investiu para mudar. É voltar a ouvir a frase “-Me tira daqui!". 
Mas afinal, qual a potência das apostas da Reforma Psiquiátrica e da PNH?

Olho novamente para a experiência italiana e seus efeitos na Reforma psiquiátrica brasileira. Vejo o quanto a vida dos usuários dos serviços de saúde mental, lá e cá, transformou-se a partir do que foi sendo inventado e criado como política de saúde mental. Da oferta exclusiva e compulsória de internação em um hospital psiquiátrico, temos, no Brasil, uma ampla e diversificada oferta de serviços e ações que contemplam diferentes dimensões e necessidades: temos os Centros de Atenção Psicossocial (em suas várias modalidades) como serviços territoriais para acolher e cuidar do sofrimento psíquico intenso; aos que habitaram por anos o manicômio temos os Serviços Residenciais Terapêuticos; para o trabalho os Projetos de Geração de Trabalho e Renda; temos ainda projetos de arte e cultura e outras tantas criações que por vários lugares vão sendo experimentadas. Pessoas que provavelmente teriam como destino viverem encarceradas em Hospitais Psiquiátricos, submetidas a um cotidiano mortífero, encontram outras possibilidades de cuidado que apostam em modos distintos de levar a vida.
Olho também para as inúmeras e exitosas experimentações que a cada dia surgem no blog humanizasus.net, evidenciando a força e a potência dos dispositivos da $\mathrm{PNH}$, produzindo efeitos na vida das pessoas que frequentam os serviços de saúde e que são acolhidas, ouvidas em suas necessidades, cuidadas e se corresponsabilizando por seu cuidado.

Estas são evidencias que demonstram que o cuidado é produção de vida, criação de mundos. Temos um imenso desafio: reativar nos encontros nossa capacidade de cuidar e tomo novamente emprestado do texto sobre Acolhimento alguns princípios que devem nos nortear:

\footnotetext{
- o coletivo como plano de produção da vida;

- o cotidiano como plano ao mesmo tempo de reprodução, de experimentação e invenção de modos de vida; e

- a indissociabilidade entre o modo de nos produzirmos como sujeitos e os modos de se estar nos verbos da vida (trabalhar, viver, amar, sentir, produzir saúde...). (Brasil, 2010, p. 8-9)
}

Nossa aposta aponta para um outro mundo possível, que se constrói nas bordas, nas fissuras, na contra-maré, nadando contra a corrente. Se o 
cotidiano reproduz assujeitamentos, heteronomias, subjetividades servis e tristes, é preciso abrir brechas e fissuras neste cenário densamente conservador, alheio e surdo aos pedidos de "- Me tira daqui!", que ainda ecoam. No cotidiano e no coletivo precisamos apostar na potência da criação e da invenção que se dá em liberdade e no bom encontro.

Pois a vida não é o que se passa apenas em cada um dos sujeitos, mas principalmente o que se passa entre os sujeitos, nos vínculos que constroem e que os constroem como potência de afetar e ser afetado. (Brasil, 2010, p.8)

Nada é natural, nada é impossível de ser mudado.

\section{Notas}

${ }^{1}$ Embora a frase apresente um erro, está escrita como ouvi tantas vezes.

${ }^{2}$ Conselho Nacional de Justiça,Ministério Público Estadual de São Paulo, Secretaria de Direitos Humanos da Presidência da República, Coordenação Nacional de Saúde Mental - Ministério da Saúde, Política Nacional de Humanização - Ministério da Saúde, Secretaria Estadual de Saúde de São Paulo, Secretaria Municipal de Saúde de Sorocaba, Conselho de Secretarias de
Saúde do Estado de São Paulo COSEMS, Conselho Estadual de Saúde, Departamento de Saúde Coletiva Universidade Estadual de Campinas, Complexo Hospitalar Ouro Verde Secretaria Municipal de Saúde de Campinas/SP, Centro de Educação dos Trabalhadores da Saúde - CETES SMS- Campinas, Universidade Federal de São Paulo - Campus Baixada Santista, Universidade Federal de São Carlos - Campus Sorocaba, Laboratório de Saúde Mental Coletiva - Faculdade de Saúde Pública - Universidade de São Paulo, Faculdade de Americana Departamento de Psicologia, Escola de Enfermagem - Universidade de São Paulo.

\section{Referências}

Brasil. Ministério da saúde. Secretaria de atenção à saúde. Núcleo técnico da política nacional de humanização. (2010). Acolhimento nas práticas de produção de saúde. (2. ed., 5. reimp.). Brasília: Ministério da Saúde.

Brasil. Ministério da Saúde. (2004). Caderno informativo do congresso brasileiro de caps. Saúde mental: cuidar em liberdade e promover a 
cidadania. Brasília: Ministério da Saúde.

Brasil. Ministério da saúde. Conselho Nacional de Saúde. (2001). Conferência Nacional de Saúde Mental. Brasília: Ministério da Saúde.

Brasil. Ministério da saúde. Secretaria de Atenção à Saúde. Núcleo Técnico da Política Nacional de Humanização. (2008).

Humanizasus: documento base para gestores e trabalhadores do sus. (4. ed.) Brasília: Ministério da Saúde.

Conselho Regional de Psicologia $6^{\text {a }}$ região. (1997). Trancar não é tratar. Liberdade: o melhor remédio. (2a ed.). São Paulo: Autor.

Nicácio, F. \& Campos, G. W. de S. (2007). Afirmação e produção de liberdade: desafio para os centros de atenção psicossocial. Rev. Ter. Ocup. São Paulo, 18(3), 143-151.

Rotelli, F.; Leonardis, O.; \& Mauri, D. (2001). Desinstitucionalização, uma outra via: a reforma psiquiátrica italiana no contexto da europa ocidental e dos "países avançados". In F. Nicácio. (Org.). Desinstitucionalização. (2 ed.). São Paulo: Hucitec.
Pasche, D. F. \& Passos, E. (2008). A importância da humanização a partir do sistema único de saúde. Rev. Saúde públ. Florianópolis, SC, 1 (1), 92-100.

Silvio Yasui: Doutor em psicologia e docente de graduação e pós-graduação em psicologia da Unesp-Assis.

E-mail: silvioyasui@gmail.com 